\title{
High-Dose Convalescent Plasma for Treatment of Severe COVID-19
}

\author{
Gil C. De Santis, Luciana Correa Oliveira, Pedro M.M. Garibaldi, Carlos E.L. Almado, \\ Julio Croda, Ghislaine G.A. Arcanjo, Érika A.F. Oliveira, Adriana C. Tonacio, Dante M. Langhi Jr., \\ José O. Bordin, Renato N. Gilio, Leonardo C. Palma, Elaine V. Santos, Simone K. Haddad, \\ Benedito P.A. Prado Jr., Marjorie Cornejo Pontelli, Rogério Gomes, Carlos H. Miranda, \\ Maria Auxiliadora Martins, Dimas T. Covas, Eurico Arruda, Benedito A.L. Fonseca, Rodrigo T. Calado
}

To assess whether high-dose coronavirus disease (COVID-19) convalescent plasma (CCP) transfusion may benefit patients with severe COVID-19, we conducted a multicenter randomized trial in Brazil. Patients with severe COVID-19 who were within 10 days of initial symptom onset were eligible. Patients in the CCP group received 3 daily doses of CCP $(600 \mathrm{~mL} / \mathrm{d})$ in addition to standard treatment; control patients received standard treatment only. Primary outcomes were death rates at days 30 and 60 of study randomization. Secondary outcomes were ventilator-free days and hospital-free days. We enrolled 107 patients: $36 \mathrm{CCP}$ and 71 control. At day 30 , death rates were $22 \%$ for CCP and $25 \%$ for the control group; at day 60 , rates were $31 \%$ for CCP and $35 \%$ for control. Needs for invasive mechanical ventilation and durations of hospital stay were similar between groups. We conclude that high-dose CCP transfused within 10 days of symptom onset provided no benefit for patients with severe COVID-19.

Author affiliations: University of São Paulo, São Paulo, Brazil (G.C. De Santis, L.C. Oliveira, E.V. Santos, S.K. Haddad, B.P.A. Prado Jr., D.T. Covas, R.T. Calado); Hospital Estadual de Serrana, Serrana, Brazil (P.M.M. Garibaldi, C.E.L. Almado); Hospital Regional do Mato Grosso do Sul, Campo Grande, Brazil (J. Croda); Fundação Oswaldo Cruz, Campo Grande (J. Croda); Universidade do Mato Grosso do Sul, Campo Grande (J. Croda, G.G.A. Arcanjo); Hospital São Camilo, São Paulo (É.A.F. Oliveira, A.C. Tonacio, D.M. Langhi Jr.); Universidade Federal de São Paulo, São Paulo (D.M. Langhi Jr., J.O. Bordin); Hospital Estadual de Américo Brasiliense, Américo Brasiliense, Brazil (R.N. Gilio); Hospital das Clínicas da Faculdade de Medicina de Ribeirão Preto, Ribeirão Preto, Brazil (L.C. Palma); Faculdade de Medicina de Ribeirão Preto da Universidade de São Paulo, São Paulo (M.C. Pontelli, R. Gomes, C.H. Miranda, M.A. Martins, E. Arruda, B.A.L. Fonseca)

DOI: https://doi.org/10.3201/eid2803.212299
C linical signs and symptoms of coronavirus disease (COVID-19) are pleomorphic, varying from none (asymptomatic) to life-threatening. Typical signs/ symptoms are fever, dry cough, dyspnea, fatigue, myalgia, anosmia, and ageusia (1). Radiography or computed tomography of the chest usually reveals bilateral pulmonary ground-glass opacifications, mainly in posterior and peripheral areas of the lungs (2). The most common laboratory test alterations are lymphopenia and elevated serum concentrations of inflammatory biomarkers and D-dimers (3). Risk factors for unfavorable outcomes are older age, concurrent conditions, and perhaps but of lesser importance, blood type A $(4,5)$. Thus far, there is no consensual agreement about specific therapy for this disease, despite several attempts to develop one $(3,6)$. More recently, antiviral agents such as MK-4482/EIDD-2801 and PF-07321332 seem to be promising $(7,8)$.

In the past, passive antibody transfer by plasma or serum transfusion has been used clinically to treat other infectious diseases, including Ebola, influenza A, severe acute respiratory syndrome, and Middle East respiratory syndrome, as well as COVID-19 (9-13). The presence of antiviral antibodies, in patient serum or in COVID-19 convalescent plasma (CCP), has been associated with more favorable clinical outcomes (14). Thus, CCP seems to be an attractive therapy because it is a potential source of neutralizing antibodies $(15,16)$.

The first case series reported from China suggested favorable outcomes for 5 patients receiving undergoing mechanical ventilation who received CCP on days 10-22 after hospital admission (17). Also in China, 10 critically ill patients received $200 \mathrm{~mL}$ of CCP with a neutralizing antibody titer of $>640$, which resulted in undetectable viral load and clinical improvement for 7 of the 10 patients (18). In a nonrandomized 
observational study that evaluated 3,082 CCP recipients, transfusion was associated with reduced mortality rates among patients who received CCP that had a higher titer against severe acute respiratory syndrome coronavirus 2 (SARS-CoV-2). Mortality rates within 30 days after CCP transfusion were $22.3 \%$ for the high-titer group, $27.4 \%$ for the medium-titer group, and $29.6 \%$ for the low-titer group. The relative risk for death was lower among patients who were not undergoing mechanical ventilation before transfusion (19). A prospective multicenter study in China that involved 103 patients with severe COVID-19 was stopped early, but initial findings suggested that CCP transfusion was associated with a higher percentage of patients being negative for SARS-CoV-2 by reverse transcription PCR (RT-PCR) at 72 hours $(87.2 \%)$ than for controls $(37.5 \%)(20)$.

Clinical improvement has been observed for Ebola patients with severe manifestations but not for those with life-threatening disease (9). Recently, a randomized trial in Argentina involving 228 patients who received CCP (median titer 3,200 ) and 105 who received placebo found that CCP transfusion did not reduce mortality rates at day 30 after randomization $(10.96 \%$ for transfused and $11.43 \%$ for nontransfused groups) (21). A recent systematic review concluded that CCP transfusion makes little or no difference, at least for patients who needed mechanical ventilation (22).

To evaluate the efficacy and safety of high-dose CCP transfusion to treat severe COVID-19, we conducted an open-label multicenter randomized controlled trial. This study was approved by the national review board (Comissão Nacional de Ética em Pesquisa, CONEP; CAAE number 30509920.0.1001.0008). Written informed consent was obtained from all patients or legal representatives. The trial was performed in accordance with the principles of the Declaration of Helsinki and the International Conference on Harmonization-Good Clinical Practice guidelines. The trial was registered at the Brazilian Registry of Clinical Trials (http://www.ensaiosclinicos.gov.br, no. RBR-7f4mt9f).

\section{Materials and Methods}

\section{Study Design}

We conducted our investigator-initiated multicenter open-label randomized controlled trial in 5 hospitals: 4 in the state of São Paulo (Hospital das Clínicas da Faculdade de Medicina de Ribeirão Preto da Universidade de São Paulo, Hospital Estadual de Américo Brasiliense, Hospital São Camilo, and Hospital
São Paulo); and 1 in Campo Grande, state of Mato Grosso do Sul (Hospital Regional de Mato Grosso do Sul). The 5 inclusion criteria were 1) diagnosis of COVID-19 based on RT-PCR results; 2) respiratory distress (oxygen saturation at room air $\leq 93 \%$, or arterial partial pressure of oxygen/fraction of inspired oxygen $\leq 300$, or requiring mechanical ventilation) resulting from pneumonia; 3 ) being within 10 days of initial symptoms; 4) age 18-80 years; and 5) signed written informed consent by the patient or legal representative. The 7 exclusion criteria were 1) history of previous severe allergy to plasma transfusion, 2) severe congestive heart failure, 3) terminal renal failure, 4) hepatic cirrhosis, 5) any severe illness expected to confer a short life expectancy, 6) participation in any other clinical trial with therapeutic intervention, and 7) immunosuppression. All included participants most likely had COVID-19 caused by the parental virus lineages (during the first wave), before emergence of the Gamma and Delta variants.

We enrolled 120 patients (40 in the CCP group and 80 in the control group), considering predicted death rates of $30 \%$ for the CCP group and $50 \%-60 \%$ for the control group. Computer-generated random numbering randomly assigned patients to receive either standard treatment (control) or CCP transfusion added to the standard treatment at a ratio of 2(control):1(CCP). For most patients, CCP transfusion was performed the day of or the day after randomization; only 2 patients received CCP 2 days after randomization. Patients and physicians were not blinded to treatment assignments. Placebo was not administered to control patients because we considered that the infused volume of saline or nonconvalescent plasma could harm the patients, especially those less tolerant to intravenous volume overload (i.e., those who were elderly, had acute kidney injury, or had other concurrent conditions). In addition, we considered it would be impossible to blind infusion of such a large volume of plasma to CCP patients. At the time of randomization, SARS-CoV-2 IgM/IgA was detected in all 65 patients who were tested and IgG was detected in $53(81.5 \%)$.

\section{Convalescent Plasma Procurement and Transfusion}

To prevent transfusion-associated lung injury, we limited CCP donor candidates to adult men or nulliparous women (23). According to regulation in Brazil, convalescent candidates may donate plasma after 15 days have passed since symptom resolution. Donor screening was similar to that used for conventional blood donation, including clinical evaluation for COVID-19 and access to peripheral veins. Plasma 
collection was performed by using a TRIMA ACCEL automated blood collection system (Terumo BCT, Inc., https://www.terumobct.com). We determined neutralizing antibody titers as described elsewhere (24). For both groups, transfused CCP median neutralizing antibody titer against SARS-CoV-2 was 128 (minimum titer of 64 in just 1 plasma unit). CCP units did not undergo pathogen reduction.

The total transfusion dose of CCP per patient was $1,800 \mathrm{~mL}$ (minimum dose 1,200 $\mathrm{mL}$ ), divided into 3 daily doses of $600 \mathrm{~mL}$ for 3 days. The $600 \mathrm{~mL}$ volumes were divided into 2 subunits of $300 \mathrm{~mL}$ or 200 and $400 \mathrm{~mL}$. All patients were randomized during days 7-10 after symptom onset, and the first CCP transfusion was administered on day 9 (range 8-10) for both groups. The first CCP transfusion had to be given by day 10 of initial symptoms.

We performed neutralizing assays for serum samples obtained from each plasma unit. In brief, we conducted virus neutralization testing with SARSCoV-2 in 96-well plates containing $5 \times 10^{4}$ cells $/ \mathrm{mL}$ of Vero cells (CCL-81). Serum samples were initially inactivated for $30 \mathrm{~min}$ at $56^{\circ} \mathrm{C}$. We used 11 serial dilutions $(1: 2$ to $1: 2,048)$. Subsequently, we mixed serum and virus (vol/vol) and preincubated the mixture at $37^{\circ} \mathrm{C}$ for $2 \mathrm{~h}$ for neutralization. We transferred the serum/virus mixture onto the confluent cell monolayer and incubated at $37^{\circ} \mathrm{C}$ at $5 \% \mathrm{CO}_{2}$. After 3 days, we analyzed the plates by using light microscopy to determine presence/absence of cytopathic effect. Neutralizing antibody titer is described as the highest serum dilution that impeded cytopathic effect.

The primary clinical outcome was death rate at days 30 and 60 from the day of randomization. Secondary outcomes were ventilator-free days and hospital-free days on days 30 and 60 after randomization and adverse reactions to plasma transfusion. Adverse events were graded according to the Common Terminology Criteria for Adverse Events version 5.0.

\section{Patient Serologic Testing and Measurement of C-Reac- tive Protein and Interleukin-6}

Using ELISA, we tested serum samples at randomization for the presence of SARS-CoV-2 IgM plus IgA (Vircell, https:/ / www.vircell.com) and IgG (Euroimmun, https://www.euroimmun.com). We measured C-reactive protein (CRP) and interleukin 6 (IL-6) on days 0 and day 7 after randomization.

\section{Statistical Analyses}

Results were expressed as mean \pm SD or median (range) and proportions according to distribution characteristics. When comparing 2 groups, we used a 2-sided unpaired Student $t$-test (parametric data) or a Mann-Whitney test (nonparametric data). For statistical comparisons of categorical variables between groups, we used the $x^{2}$ test. We generated overall survival estimates by using the KaplanMeier method and assessed differences between the groups by using the log-rank test. We considered results to be statistically different when the $p$ value was $<0.05$ (by 2-tailed testing). We used GraphPAD Prism version 8.4 .3 (https://www.graphpad.com) for statistical analyses.

\section{Results}

During April-November 2020, we enrolled 110 patients at 5 centers. Because recruiting became more difficult as the number of new cases substantially decreased, we halted recruitment early, before reaching 120 participants. Of the 110, we excluded 3 participants from analysis: 1 in the CCP group did not receive plasma transfusion; 1 in the control group withdrew consent; and 1 in the control group was intubated and underwent invasive mechanical ventilation for neurologic reasons, not pneumonia, a prerequisite for inclusion in this study (Figure 1). The median duration of symptoms before randomization was 8 (range 7-10) days. The median age at randomization was 60 (range 24-80) years; male:female ratio was 1.7:1.0 (Table 1). All patients had severe COVID-19 ( $\geq 6$ points according to the World Health Organization severity ordinal scale (https://www. who.int/docs/default-source/documents/emergencies/minimalcoreoutcomemeasure.pdf).

Because of low body weight $(50 \mathrm{~kg}), 2$ patients received a total of 1,200 $\mathrm{mL}$ of CCP. For 2 other patients, CCP doses were divided over 4 days, as allowed by protocol. No participant was unable to be reached during follow-up.

\section{Death Rates}

A total of $36(34 \%)$ of the 107 enrolled patients died during hospitalization, 10 after day 30 (median 45.5, range 31-50 days); 3 were in the CCP group and 7 were in the control group $(\mathrm{p}=1.00)$. At randomization day 30 , death rates were $22 \%$ for the CCP group and $25 \%$ for the control group (odds ratio [OR] 0.84, 95\% CI 0.32-2.25; $\mathrm{p}=0.81$ ). At day 60 , death rates were $31 \%$ for the CCP group and $35 \%$ for the control group (OR 0.81, 95\% CI, 0.35-1.86; $\mathrm{p}=0.67$ ) (Table 2). We performed a nonscheduled analysis of death rates on day 21 after randomization because at that point it seemed that there could be a difference between the groups, as suggested by the survival curve (Figure 2). We determined that on day 21 , there had been a total 
of $3 / 36(8.33 \%)$ deaths in the CCP group and $14 / 71$ $(19.7 \%)$ deaths in the control group (OR 0.37, 95\% CI $0.11-1.3 ; \mathrm{p}=0.17)$.

\section{Duration of Mechanical Ventilation and Hospitalization} At randomization day 30, the number of days free of invasive mechanical ventilation was 12.5 (range $0-30$ ) for the CCP group and 12 (range $0-30$ ) for the control group ( $p=0.82$ ); at day 60 , the number of days was $42.5(0-60)$ for the CCP group and $39(0-60)$ for the control group $(p=0.80)$ (Table 2$)$. We did not observe differences in hospital stay duration at days 30 and 60. At day 30, hospital-free days were $3(0-24)$ days for the CCP group and 0 (0-28) days for the control group ( $\mathrm{p}=0.27$ ); at day 60 , hospital-free days were $30.5(0-53)$ days for the CCP group and $21.0(0-58)$ days for the control group $(\mathrm{p}=0.43)$ (Table 2$)$.

\section{Inflammatory Biomarkers}

CRP concentrations were elevated at the time of randomization (day 0 ) and decreased significantly by day 7 in a similar fashion in both groups. The medians (interquartile ranges [IQRs]) on day 0 were 11.4 (3.31-20.55) $\mathrm{mg} / \mathrm{dL}$ for the CCP group and 12.82 $(5.05-24.40) \mathrm{mg} / \mathrm{dL}$ for the control group $(\mathrm{p}=0.55)$. On day 7, medians (IQRs) were $2.53(0.72-6.17) \mathrm{mg} /$ $\mathrm{dL}$ for the CCP group and 2.75 (1.19-6.15) $\mathrm{mg} / \mathrm{dL}$ for the control group $(\mathrm{p}=0.52)$ (Figure 3, panel A). IL-6 concentrations were elevated on days 0 and 7 and, likewise, did not differ significantly between groups. IL-6 medians (IQRs) were $15.20(6.99-26.00) \mathrm{pg} / \mathrm{mL}$ on day 0 and $13.80(7.95-37.95) \mathrm{pg} / \mathrm{mL}$ on day $7(\mathrm{p}=$

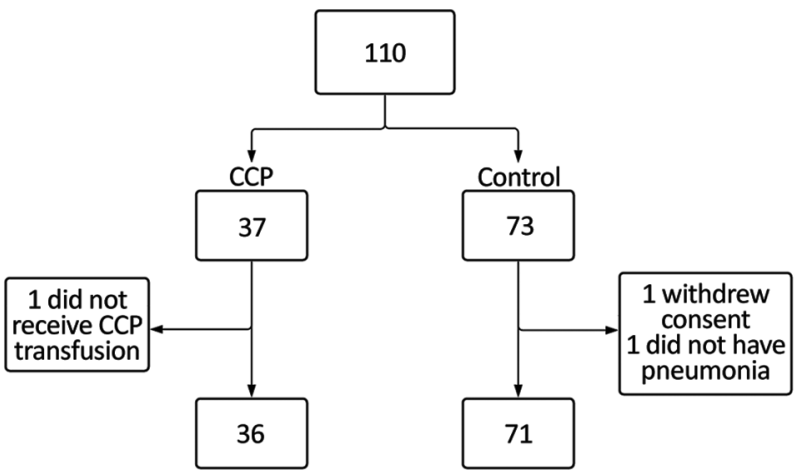

Figure 1. Enrollment and randomization process for study of highdose CCP for treatment of severe COVID-19, Brazil. COVID-19, coronavirus disease; CCP, COVID-19 convalescent plasma.

$0.88)$ for the CCP group and $16.00(6.61-30.40) \mathrm{pg} / \mathrm{mL}$ on day 0 and $18.65(6.40-54.85) \mathrm{pg} / \mathrm{mL}$ on day $7(\mathrm{p}=$ 0.72 ) for the control group (Figure 3, panel B).

\section{Safety}

No serious adverse reactions attributable to CCP transfusion were observed during study follow-up. We considered severe reactions to be greater than grade 3 according to the Common Terminology Criteria for Adverse Events version 5.0 (https://ctep. cancer.gov).

\section{Discussion}

In this randomized clinical trial, transfusion of highdose CCP did not reduce death rates, hospitalization durations, or number of days receiving mechanical ventilation for patients with very severe COVID-19.

\begin{tabular}{|c|c|c|c|}
\hline Variable & $\mathrm{CCP}, \mathrm{n}=36$ & Control, $\mathrm{n}=71$ & $\mathrm{p}$ value \\
\hline \multicolumn{4}{|l|}{ Demographic } \\
\hline \multirow{2}{*}{\multicolumn{4}{|c|}{ Sex, no. (\%) }} \\
\hline & & & \\
\hline $\mathrm{M}$ & $23(63.89)$ & $44(64.79)$ & 1.0 \\
\hline $\mathrm{F}$ & $13(36.11)$ & $27(35.21)$ & \\
\hline Body mass index, median (range), $\mathrm{kg} / \mathrm{m}^{2}$ & $29.75(18.37-58.00)$ & $29.41(20.31-74.22)$ & 0.88 \\
\hline Weight, median (range), kg & $85(50-156)$ & $85(50-190)$ & 0.95 \\
\hline \multicolumn{4}{|l|}{ Underlying conditions } \\
\hline Hypertension, no. (\%) & $19(52.78)$ & $41(57.75)$ & 0.68 \\
\hline Diabetes mellitus, no. (\%) & $12(33.33)$ & $29(40.85)$ & 0.53 \\
\hline Renal replacement therapy, no. (\%) & $13(36.11)$ & 27 (38.03) & 1.0 \\
\hline SAPS-3 score, median (range)† & $56(37-94)$ & $68(39-100)$ & 0.15 \\
\hline SOFA score, median (range) & $7.5(1.0-14.0)$ & $9.0(2.0-14.0)$ & 0.17 \\
\hline \multicolumn{4}{|l|}{ Clinical characteristic } \\
\hline Mechanical ventilation, no. (\%) & $32(88.88)$ & $58(81.69)$ & 0.41 \\
\hline D-dimer, median (range), $\mu \mathrm{g} / \mathrm{mL} \ddagger$ & $1.02(0.27-10.00)$ & $1.65(0.39-20.00)$ & 0.12 \\
\hline Blood type O/A§ & $13 / 18$ & $31 / 27$ & 0.38 \\
\hline Blood type, $\mathrm{rH}$ positive/negative $\S$ & $33 / 3$ & $67 / 3$ & 0.41 \\
\hline \multicolumn{4}{|c|}{$\begin{array}{l}{ }^{*} \mathrm{CCP}, \text { COVID-19 convalescent plasma; COVID-19, coronavirus disease; CRP: C-reactive protein; SAPS-3 score, Simplified Acute Physiology Score } 3 \text { at } \\
\text { admission to intensive care unit; SOFA score, Sequential Organ Failure Assessment (on day of randomization) for } 20 \text { CCP and } 41 \text { control patients. } \\
\dagger 31 \mathrm{CCP} \text { and } 57 \text { control patients. } \\
\ddagger 23 \text { CCP and } 39 \text { control patients on day of randomization. } \\
\S 106 \text { patients. }\end{array}$} \\
\hline
\end{tabular}


Table 2. Clinical outcomes for participants in study of high-dose convalescent plasma for treatment of severe COVID-19, Brazil ${ }^{*}$

\begin{tabular}{|c|c|c|c|}
\hline Outcome & $\mathrm{CCP}, \mathrm{n}=36$ & Control, $n=71$ & $\mathrm{p}$ value \\
\hline Death at HD 30, no. (\%) & $8(22.22)$ & $18(25.35)$ & 0.81 \\
\hline Death at HD 60, no. (\%) & $11(30.55)$ & $25(35.21)$ & 0.67 \\
\hline Ventilator-free days at HD 30† & $12.5(0-30)$ & $12.0(0-30)$ & 0.82 \\
\hline Ventilator-free days at HD $60 \ddagger$ & $42.5(0-60)$ & $39.0(0-60)$ & 0.80 \\
\hline Hospital-free days at HD 30† & $3(0-24)$ & $0(0-28)$ & 0.27 \\
\hline Hospital-free days at HD $60 \S$ & $30.5(0-53)$ & $21.0(0-58)$ & 0.45 \\
\hline $\begin{array}{l}{ }^{*} \mathrm{CCP}, \mathrm{COVID}-19 \text { convalescent plas } \\
\dagger 35 \mathrm{CCP} \text { and } 70 \text { control samples. } \\
\ddagger 33 \mathrm{CCP} \text { and } 67 \text { control samples. } \\
\S 33 \text { CCP and } 69 \text { control samples. }\end{array}$ & ID, hospitaliza & & \\
\hline
\end{tabular}

We detected a slightly reduced death rate, but it did not reach statistical significance. Serum inflammatory biomarkers were also reduced, but CCP transfusion did not influence the reduction. All enrolled patients experienced severe respiratory failure resulting from viral pneumonia, and most of them were undergoing invasive mechanical ventilation. Most patients had $\geq 1$ concurrent condition, which increases mortality rates (25). More than one third of the enrolled patients needed kidney replacement therapy (hemodialysis). These characteristics emphasize the extreme severity of COVID-19 in the patients in our cohort. Participants received $\mathrm{CCP}$ as soon as possible, always within 10 days of symptom onset. This transfusion window was considered adequate at the time of the study planning and execution, especially when compared with other studies, in which transfusion occurred as late as day 39 (9). Of note, we observed that most trials evaluated the death rate at days 28 or 30 of randomization, but we observed that more than one fourth of the deaths in our study occurred during days 30-60.

Our results challenge those of nonrandomized studies previously conducted at the beginning of the pandemic (17), as well as those of a large nonrandomized study involving $>3,000$ US patients, which suggested that CCP could be an efficacious treatment

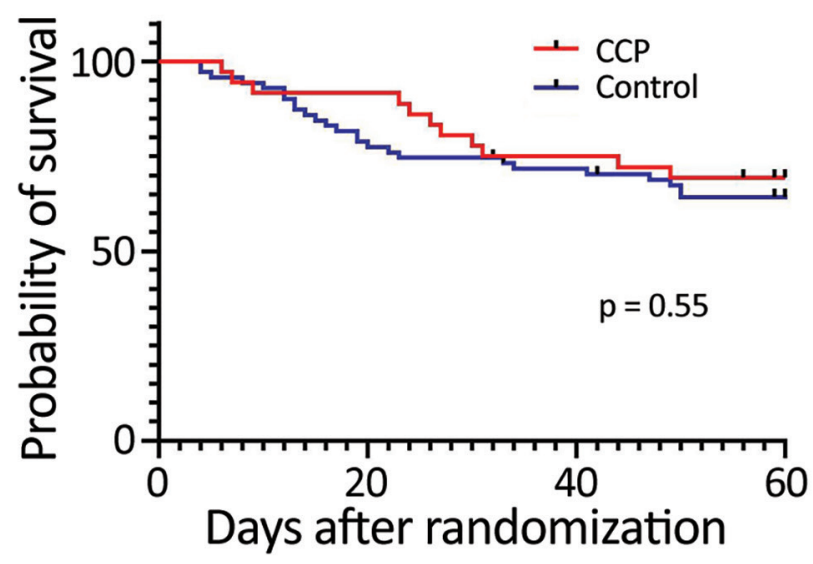

Figure 2. Probability of survival after randomization for study of high-dose CCP for treatment of severe COVID-19. COVID-19, coronavirus disease; CCP, COVID-19 convalescent plasma. for COVID-19 (19). In our study, mortality rate on day 30 was lower among patients who received CCP with higher titers of SARS-CoV-2 antibodies (22.3\%) than among those who received CCP with medium $(27.4 \%)$ or low $(29.6 \%)$ titers. We observed a lower mortality rate for the high-titer group than for the low-titer group among patients who had not received mechanical ventilation before transfusion (relative risk $0.66,95 \%$ CI $0.48-0.91$ ) but not among patients who had received mechanical ventilation (relative risk $1.02,95 \%$ CI 0.78-1.32) (19).

Our findings contrast with those of a previous multicenter randomized trial involving 103 participants (52 received CCP, 51 received standard treatment alone), which showed clinical improvement within 28 days in the subgroup of patients with severe disease who received CCP but not in the subgroup with life-threatening disease (9). In that study, CCP transfusion resulted in a higher rate of conversion to negative viral PCR results at 72 hours, suggesting potential benefit. In our study, most patients had life-threatening disease, which may explain, at least in part, the different outcomes. It is possible that patients with less severe disease may benefit from CCP. Nevertheless, in our study, an interim nonplanned analysis of death rates on day 21 suggested a possible benefit of CCP, similar to that observed by others (26-28), which was not confirmed by subsequent analyses. This finding raises the questions whether CCP provided a temporary benefit that was lost during the disease course and, if so, whether CCP should be transfused for a longer period during the disease.

Our study findings are in accordance with those of a randomized study in Argentina involving 228 patients who received CCP and 105 who received placebo, which did not show any survival benefits among patients receiving CCP (21). Of note, patient profiles for that study indicated less severe disease than did profiles for patients in our study. In the Argentina study, patients receiving mechanical ventilation were excluded, conflicting with the hypothesis that patients with less severe disease may benefit from CCP. The difference in disease severity also 
High-Dose Convalescent Plasma for Severe COVID-19
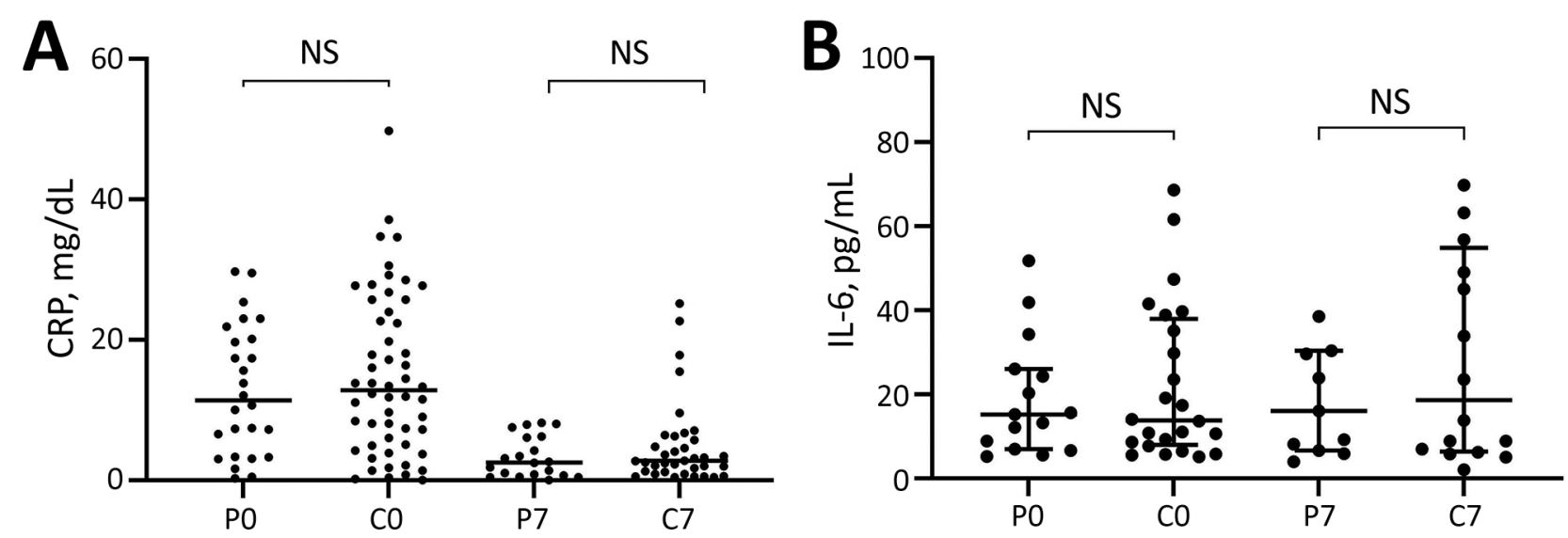

Figure 3. Scatter plots of inflammatory biomarker levels among participants in study of high-dose convalescent plasma for treatment of severe COVID-19, Brazil. A) C-reactive protein (CRP); total 80 patients (26 CCP, 54 control) on day 0 and 56 (20 CCP, 36 control) on day 7. B) Interleukin-6 (IL-6); total 39 patients (15 CCP, 24 control) on day 0 and 27 (11 CCP, 16 control) on day 7 . Horizontal bars indicate medians. C0, control group day 0; C7, control group day 7; COVID-19, coronavirus disease; CCP, COVID-19 convalescent plasma; NS, not significant; P0, convalescent plasma group day 0; P7, convalescent plasma group day 7

may explain the higher mortality rate observed in our study $(33.64 \%)$ compared with that in the Argentina trial $(10.96 \%)$. A study in Brazil also did not find clinical improvement in the group that received CCP (29). Our results are in agreement with those obtained in another randomized study, in which 464 participants with moderate COVID-19 were assigned to receive 2 doses of $200 \mathrm{~mL}$ CCP $(\mathrm{n}=235)$ or standard treatment ( $n=229$ ) (30). The authors of that study evaluated the composite outcomes of progression to severe disease and observed that CCP transfusion was not associated with clinical benefit. A recent randomized clinical trial with $>16,000$ enrolled patients showed that CCP transfusion did not improve survival rates (31). In that trial, the 28 -day mortality rate was $24 \%$ for both groups (1,399 of 5,795 vs. 1,408 of 5,763; $p=0.95)$. Also, CCP transfusion had no significant effect on the proportion of patients discharged from the hospital. In that trial, only $5 \%$ of the patients in each group were receiving invasive mechanical ventilation; however, this percent value meant that administration of $\mathrm{CCP}$ to $>550$ patients did not influence outcomes in that subgroup of patients. Last, a recently published multicenter randomized trial (patients hospitalized with moderate disease up to day 12 from symptom onset) also found that CCP did not reduce the risk for intubation or death at day 30 in hospitalized patients with moderate disease (32).

The first strength of our study is the randomized design, which provided homogeneity and adequate comparison between groups with similar characteristics and disease severity. Second, we used only CCP with adequate neutralizing antibody titers. Third, the transfused CCP volume was high, making it less likely that the lack of response could be attributable to a low dose of neutralizing antibodies. Fourth, the patients received CCP transfusion up to day 10 after symptom onset, which was relatively early in comparison with other studies $(9,17)$. However, one may hypothesize that up to 10 days for $\mathrm{CCP}$ transfusion may be too late for those with the most severe disease. It is possible that by day 9-10 after symptom onset, most patients would have endogenous antibodies, which was determined for patients in our study and has been shown by others (A. Gharbharan et al., unpub. data, http:/ / medrxiv.org/lookup/doi /10.1101/2020.07.01.20139857). Perhaps it would be more effective to administer CCP earlier in disease, especially for patients considered to be at higher risk for unfavorable outcome. Libster et al. recently demonstrated that early CCP transfusion (within 72 hours of symptom onset) in older patients with mild COVID-19 reduced progression to severe respiratory disease by $48 \%$ (33). Another group also demonstrated reduced hospitalizations for those who received early CCP transfusion with high titers of neutralizing antibodies (D.J. Sullivan, unpub. data, https:// www.medrxiv.org/content/10.1101/2021.12.10.2126 7485v1). These results seem logical because a more effective clinical response with early CCP transfusion, before the spontaneous appearance of antibodies, would be expected.

Among the limitations of our study, the number of patients enrolled was relatively small. However, because we anticipated difficulties obtaining the necessary amount of CCP to be administered to each patient, we decided to assign the participants at a ratio of 2 control to $1 \mathrm{CCP}$. Another weakness 
was that the study was not blinded. However, infusion of a high volume of intravenous placebo could have been harmful to recipients. Patients in the control group should not be exposed to additional risk as a consequence of their participation in a clinical trial. Another limitation was that our patients already had SARS-CoV-2 antibodies when they received CCP transfusion, which could explain the absence of response to this therapy.

In conclusion, our study found that high-dose convalescent plasma transfusion provided no benefits for patients with severe COVID-19. Transfusions did not reduce death rates at days 30 and 60 from randomization, time receiving mechanical ventilation, or length of hospital stay for patients with severe COVID-19.

\section{Acknowledgments}

We thank Nathália Cristine André and Tatiane Marazia for their assistance.

This work was supported by Fundação de Amparo à Pesquisa do Estado de São Paulo (grant no. 20/05367-3).

\section{About the Author}

Dr. De Santis is a clinical hematologist at the University of São Paulo. His research interests include blood transfusion and cellular therapy, such as laboratory support for hematopoietic stem cell transplantation.

\section{References}

1. Izda V, Jeffries MA, Sawalha AH. COVID-19: a review of therapeutic strategies and vaccine candidates. Clin Immunol. 2021;222:108634. https://doi.org/10.1016/j.clim.2020.108634

2. Chung M, Bernheim A, Mei X, Zhang N, Huang M, Zeng X, et al. CT imaging features of 2019 novel coronavirus (2019nCoV). Radiology. 2020;295:202-7. https://doi.org/10.1148/ radiol.2020200230

3. Wang Y, Zhang D, Du G, Du R, Zhao J, Jin Y, et al. Remdesivir in adults with severe COVID-19: a randomised, double-blind, placebo-controlled, multicentre trial. Lancet. 2020;395:1569-78. https://doi.org/10.1016/S0140-6736(20)31022-9

4. Garibaldi PMM, Oliveira LC, Fonseca BA, AuxiliadoraMartins M, Miranda CH, Almado CEL, et al. Histo-blood group A is a risk factor for severe COVID-19. Transfus Med. 2021 Jun 3; [Epub ahead of print]. https:// doi.org/10.1111/ tme.12796

5. Zhou F, Yu T, Du R, Fan G, Liu Y, Liu Z, et al. Clinical course and risk factors for mortality of adult inpatients with COVID-19 in Wuhan, China: a retrospective cohort study. Lancet. 2020;395:1054-62. https://doi.org/10.1016/ S0140-6736(20)30566-3

6. Horby P, Lim WS, Emberson JR, Mafham M, Bell JL, Linsell L, et al.; RECOVERY Collaborative Group. Dexamethasone in hospitalized patients with Covid-19. N Engl J Med. 2021;384:693-704. https://doi.org/10.1056/ NEJMoa2021436

7. Cox RM, Wolf JD, Plemper RK. Therapeutically administered ribonucleoside analogue MK-4482/EIDD-2801 blocks
SARS-CoV-2 transmission in ferrets. Nat Microbiol. 2021;6:11-8. https://doi.org/10.1038/s41564-020-00835-2

8. Owen DR, Allerton CMN, Anderson AS, Aschenbrenner L, Avery M, Berritt S, et al. An oral SARS-CoV-2 $\mathrm{M}^{\text {pro }}$ inhibitor clinical candidate for the treatment of COVID-19. Science. 2021;374:1586-93. https://doi.org/10.1126/science.abl4784

9. Lee JS, Adhikari NKJ, Kwon HY, Teo K, Siemieniuk R, Lamontagne F, et al. Anti-Ebola therapy for patients with Ebola virus disease: a systematic review. BMC Infect Dis. 2019;19:376. https://doi.org/10.1186/s12879-019-3980-9

10. Casadevall A, Scharff MD. Serum therapy revisited: animal models of infection and development of passive antibody therapy. Antimicrob Agents Chemother. 1994;38:1695-702. https:/ / doi.org/10.1128/AAC.38.8.1695

11. Hung IF, To KK, Lee C-K, Lee K-L, Chan K, Yan W-W, et al. Convalescent plasma treatment reduced mortality in patients with severe pandemic influenza A (H1N1) 2009 virus infection. Clin Infect Dis. 2011;52:447-56. https://doi.org/10.1093/cid/ciq106

12. Arabi YM, Hajeer AH, Luke T, Raviprakash K, Balkhy H, Johani $S$, et al. Feasibility of using convalescent plasma immunotherapy for MERS-CoV infection, Saudi Arabia. Emerg Infect Dis. 2016;22:1554-61. https://doi.org/10.3201/ eid2209.151164

13. Roback JD, Guarner J. Convalescent plasma to treat COVID-19: possibilities and challenges. JAMA. 2020;323:1561-2. https:// doi.org/10.1001/jama.2020.4940

14. Yokoyama APH, Wendel S, Bonet-Bub C, Fachini RM, Dametto APF, Blumm F, et al. COVID-19 convalescent plasma cohort study: evaluation of the association between both donor and recipient neutralizing antibody titers and patient outcomes. Transfusion. 2021;61:2295-306. https:/ / doi.org/10.1111/trf.16573

15. Bloch EM, Shoham S, Casadevall A, Sachais BS, Shaz B, Winters JL, et al. Deployment of convalescent plasma for the prevention and treatment of COVID-19. J Clin Invest. 2020;130:2757-65. https://doi.org/10.1172/JCI138745

16. Stadlbauer D, Amanat F, Chromikova V, Jiang K, Strohmeier S, Arunkumar GA, et al. SARS-CoV-2 seroconversion in humans: a detailed protocol for a serological assay, antigen production, and test setup. Curr Protoc Microbiol. 2020;57:e100. https://doi.org/10.1002/cpmc.100

17. Shen C, Wang Z, Zhao F, Yang Y, Li J, Yuan J, et al. Treatment of 5 critically ill patients with COVID-19 with convalescent plasma. JAMA. 2020;323:1582-9. https://doi.org/10.1001/jama.2020.4783

18. Duan K, Liu B, Li C, Zhang H, Yu T, Qu J, et al. Effectiveness of convalescent plasma therapy in severe COVID-19 patients. Proc Natl Acad Sci U S A. 2020;117:94906. https://doi.org/10.1073/pnas.2004168117

19. Joyner MJ, Carter RE, Senefeld JW, Klassen SA, Mills JR, Johnson PW, et al. Convalescent plasma antibody levels and the risk of death from COVID-19. N Engl J Med. 2021;384:1015-27. https://doi.org/10.1056/NEJMoa2031893

20. Li L, Zhang W, Hu Y, Tong X, Zheng S, Yang J, et al. Effect of convalescent plasma therapy on time to clinical improvement in patients with severe and life-threatening COVID-19: a randomized clinical trial. JAMA. 2020;324:46070. https://doi.org/10.1001/jama.2020.10044

21. Simonovich VA, Burgos Pratx LD, Scibona P, Beruto MV, Vallone MG, Vázquez C, et al.; PlasmAr Study Group. A randomized trial of convalescent plasma in COVID-19 severe pneumonia. N Engl J Med. 2021;384:619-29. https://doi.org/10.1056/NEJMoa2031304

22. Piechotta V, Iannizzi C, Chai KL, Valk SJ, Kimber C, Dorando $\mathrm{E}$, et al. Convalescent plasma or hyperimmune 
immunoglobulin for people with COVID-19: a living systematic review [cited 2021 Dec 3]. https:/ / www.cochranelibrary.com/ cdsr/doi/10.1002/14651858.CD013600.pub4/full

23. Roubinian N. TACO and TRALI: biology, risk factors, and prevention strategies. Hematology (Am Soc Hematol Educ Program). 2018;2018:585-94. https:// doi.org/10.1182/ asheducation-2018.1.585

24. Wendel S, Kutner JM, Machado R, Fontão-Wendel R, Bub C, Fachini R, et al. Screening for SARS-CoV-2 antibodies in convalescent plasma in Brazil: preliminary lessons from a voluntary convalescent donor program. Transfusion. 2020;60:2938-51. https://doi.org/10.1111/trf.16065

25. Rosenthal N, Cao Z, Gundrum J, Sianis J, Safo S. Risk factors associated with in-hospital mortality in a us national sample of patients with COVID-19. JAMA Netw Open. 2020;3:e2029058. https://doi.org/10.1001/ jamanetworkopen.2020.29058

26. Avendaño-Solá C, Ramos-Martínez A, Muñez-Rubio E, Ruiz-Antorán B, Malo de Molina R, Torres F, et al. ConPlas-19 Study Group. A multicenter randomized open-label clinical trial for convalescent plasma in patients hospitalized with COVID-19 pneumonia. J Clin Invest. 2021;131:e152740. https://doi.org/10.1172/JCI152740

27. O'Donnell MR, Grinsztejn B, Cummings MJ, Justman JE, Lamb MR, Eckhardt CM, et al. A randomized double-blind controlled trial of convalescent plasma in adults with severe COVID-19. J Clin Invest. 2021;131:150646. https://doi.org/ 10.1172/JCI150646

28. Körper S, Weiss M, Zickler D, Wiesmann T, Zacharowski K, Corman VM, et al.; CAPSID Clinical Trial Group. Results of the CAPSID randomized trial for high-dose convalescent plasma in patients with severe COVID-19. J Clin Invest. 2021;131:e152264. https://doi.org/10.1172/JCI152264

29. Sekine L, Arns B, Fabro BR, Cipolatt MM, Machado RRG, Durigon EL, et al.; PLACOVID Study Group. Convalescent plasma for COVID-19 in hospitalised patients: an openlabel, randomised clinical trial. Eur Respir J. 2021 Aug 12 [Epub ahead of print]. https://doi.org/10.1183/ 13993003.01471-2021

30. Agarwal A, Mukherjee A, Kumar G, Chatterjee P, Bhatnagar T, Malhotra P; PLACID Trial Collaborators. Convalescent plasma in the management of moderate COVID-19 in adults in India: open label phase II multicentre randomised controlled trial (PLACID Trial). BMJ. 2020;371:m3939. https:// doi.org/10.1136/bmj.m3939

31. Abani O, Abbas A, Abbas F, Abbas M, Abbasi S, Abbass $\mathrm{H}$, et al.; RECOVERY Collaborative Group. Convalescent plasma in patients admitted to hospital with COVID-19 (RECOVERY): a randomised controlled, open-label, platform trial. Lancet. 2021;397:2049-59. https://doi.org/10.1016/ S0140-6736(21)00897-7

32. Bégin $P$, Callum J, Jamula E, Cook R, Heddle NM, Tinmouth A, et al.; CONCOR-1 Study Group. Convalescent plasma for hospitalized patients with COVID-19: an openlabel, randomized controlled trial. Nat Med. 2021;27:2012-24. https:// doi.org/10.1038/s41591-021-01488-2

33. Libster R, Pérez Marc G, Wappner D, Coviello S, Bianchi A, Braem V, et al.; Fundación INFANT-COVID-19 Group. Early high-titer plasma therapy to prevent severe COVID-19 in older adults. N Engl J Med. 2021;384:610-8. https://doi.org/10.1056/NEJMoa2033700

Address for correspondence: Gil C. De Santis, Rua Tenente Catão Roxo, 2501 Ribeirão Preto, 14051-140 SP, Brazil; email: gil@hemocentro.fmrp.usp.br

\section{EID podcast Heartland Virus Transmission, New York}

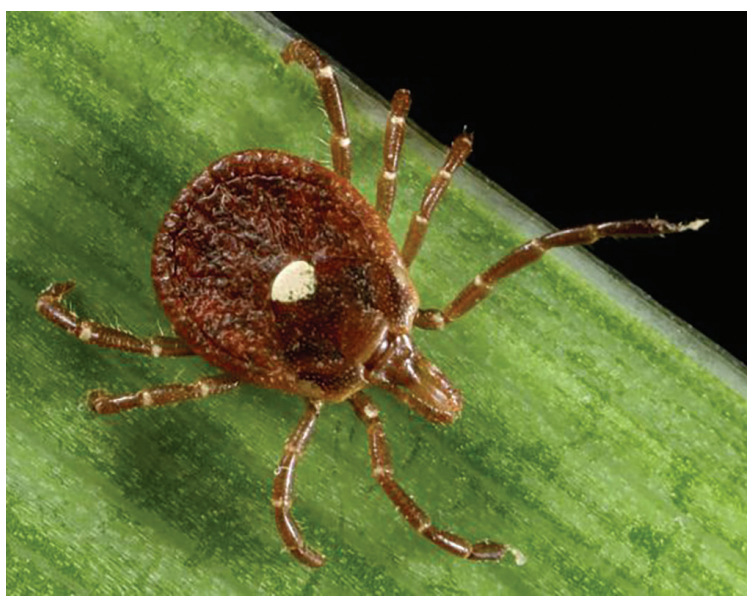

During the fall of 2018, a case of Heartland virus was detected in New York. Spread by the lone star tick, human cases of Heartland virus have primarily occurred in the Midwest and southeastern states. The discovery of Heartland virus in the northeast emphasizes a need for disease surveillance anywhere lone star ticks are established or emerging.

In this EID podcast, Alan Dupuis, a research scientist at the New York State Department of Health in Albany, and EID's Sarah Gregory discuss the detection and surveillance of Heartland virus in New York.

\section{Visit our website to listen: http: / /go.usa.gov/xeGTF} EMERGING INFECTIOUS DISEASES 